Authors have nothing to disclose with regard to commercial support.

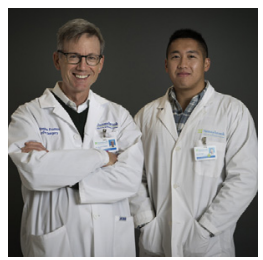

\section{CABLE TIES FOR CHEST CLOSURE: ZIPFIX OR ZIPFAIL?}

\section{To the Editor:}

We read with great interest the randomized clinical trial (RCT) conducted by Marasco and colleagues comparing ZIPFIX (DePuy Synthes CMF, West Chester, $\mathrm{Pa}$, a polymer cable tie system, with traditional wire cerclage in primary sternal closure after cardiac surgery in 118 patients. ${ }^{1}$ The authors reported no difference in postoperative pain (the primary outcome) despite more movement on ultrasonographic examination (the secondary outcome) in the ZipFix group. The authors conclude that ZIPFIX provides a reliable closure without any demonstrable benefit compared with wires.

The results of this study are strikingly different from those published by Nezafati and colleagues in Heart, Lung \& Circulation. ${ }^{2}$ In a RCT of 326 patients randomized to ZIPFIX or wire cerclage, the authors reported improved pain scores with ZIPFIX. More impressive, the authors reported a significant reduction in sternal dehiscence ( 0 in the ZIPFIX group and 5 in the wire group; $P<.001$ ). Can Marasco and colleagues provide any insight into the heterogeneity in the results of these 2 studies? Is it simply a problem of sample size or was there a difference in closure technique, generational differences in the ZIPFIX closure device, or some other factor that resulted in divergent results.

Drawing conclusions from this study alone would suggest that ZIPFIX is a dominated strategy in health economics speak-the use of ZIPFIX comes at a higher cost to the traditional treatment strategy of wires without providing any additional benefit. In fact, although the authors conclude that ZIPFIX might provide a reliable closure, their ultrasonographic outcome suggests otherwise because there was more movement compared with wire cerclage. An RCT comparing rigid plate fixation

\footnotetext{
The Editor welcomes submissions for possible publication in the Letters to the Editor section that consist of commentary on an article published in the Journal or other relevant issues. Authors should: • Include no more than 500 words of text, three authors, and five references. • Type with double-spacing. • See http://jtcs.ctsnetjournals.org/ misc/ifora.shtml for detailed submission instructions. • Submit the letter electronically via jtcvs.editorialmanager.com. Letters commenting on an article published in the JTCVS will be considered if they are received within 6 weeks of the time the article was published. Authors of the article being commented on will be given an opportunity of offer a timely response ( 2 weeks) to the letter. Authors of letters will be notified that the letter has been received. Unpublished letters cannot be returned.
}

with wire cerclage showed improved sternal healing and lower rates of sternal complications with plates, ${ }^{3}$ highlighting that adhering to the basic principles of fracture management, reapproximation, stabilization, and immobilization, remains key to optimal bone healing. Perhaps understanding how this study differs than the results of the published literature might shed light on how ZIPFIX might be used to improve sternal healing after median sternotomy.

Derrick Y. Tam, MD

Stephen E. Fremes, MD, MSc

Division of Cardiac Surgery

Department of Surgery

Schulich Heart Centre

Sunnybrook Health Sciences Centre

University of Toronto

Toronto, Ontario, Canada

\section{References}

1. Marasco SF, Fuller L, Zimmet A, McGiffin D, Seitz M, Ch'ng S, et al. Prospective randomized controlled trial of polymer cable ties versus standard wire closure of midline sternotomy. J Thorac Cardiovasc Surg. 2018;156:1589-95.

2. Nezafati P, Shomali A, Kahrom M, Omidvar Tehrani S, Dianatkhah M Nezafati MH. ZipFix versus conventional sternal closure: one-year follow-up. Heart Lung Circ. February 8, 2018 [Epub ahead of print].

3. Allen KB, Thourani VH, Naka Y, Grubb KJ, Grehan J, Patel N, et al. Randomized, multicenter trial comparing sternotomy closure with rigid plate fixation to wire cerclage. J Thorac Cardiovasc Surg. 2017;153:888-96.e1.

https://doi.org/10.1016/j.jtcvs.2018.05.030

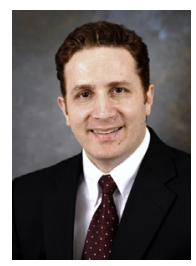

\section{POLYMER CABLE TIE CLOSURE OF THE STERNUM: IS IT AN ACCEPTABLE FIX? Reply to the Editor:}

It was enlightening to read the insightful letter to the Editor by Tam and Fremes ${ }^{1}$ regarding the randomized, controlled trial (RCT) conducted by Marasco and colleagues ${ }^{2}$ to compare ZIPFIX ties (DePuy Synthes, West Chester, Pa) with traditional wire cerclage for primary sternal closure. The investigators reported no difference in postoperative pain between the 2 groups (primary outcome). Follow-up ultrasonography, however, showed more movement in the ZIPFIX group, suggesting sternal instability. Notably, ultrasonographic follow-up in this study was incomplete, and ultrasonographically documented sternal dehiscence was not the primary outcome.

Another recent RCT, conducted by Nezafati and colleagues $^{3}$ and published in Heart, Lung and Circulation, also compared ZIPFIX with wire cerclage and found remarkably different results. Those investigators reported that the patients who underwent ZIPFIX fixation had lower pain scores $(P<.001)$ and significantly less sternal 
Author has nothing to disclose with regard to commercial support.
RCT might help us determine what role, if any, sternal ZIPFIX should have in chest closure.

Shuab Omer, MD

Division of Cardiothoracic Surgery

Baylor College of Medicine

Michael E DeBakey VA Medical Center

Houston, Tex

\section{References}

1. Tam DY, Fremes SE. Cable ties for chest closure: ZIPFIX or ZIPFAIL? J Thorac Cardiovasc Surg. 2018;156:1611.

2. Marasco SF, Fuller L, Zimmet A, McGiffin D, Seitz M, Ch'ng S, et al. Prospective, randomized, controlled trial of polymer cable ties versus standard wire closure of midline sternotomy. J Thorac Cardiovasc Surg. 2018;156:1589-95.

3. Nezafati P, Shomali A, Kahrom M, Omidvar Tehrani S, Dianatkhah M, Nezafati MH. ZipFix versus conventional sternal closure: one-year follow-up. Heart Lung Circ. February 8, 2018 [Epub ahead of print].

4. Schimmer C, Reents W, Elert O. Primary closure of median sternotomy: a survey of all German surgical heart centers and a review of the literature concerning sternal closure technique. Thorac Cardiovasc Surg. 2006;54:408-13.

5. Allen KB, Thourani VH, Naka Y, Grubb KJ, Grehan J, Patel N, et al. Randomized, multicenter trial comparing sternotomy closure with rigid plate fixation to wire cerclage. J Thorac Cardiovasc Surg. 2017;153:888-96.e1.

6. Tam DY, Nedadur R, Yu M, Yanagawa B, Fremes SE, Friedrich JO. Rigid plate fixation versus wire cerclage for sternotomy after cardiac surgery: a meta-analysis. Ann Thorac Surg. March 22, 2018 [Epub ahead of print].

https://doi.org/10.1016/j.jtcvs.2018.05.067 detection of sternal click on physical examination; use of this criterion by itself could have missed a lot of malunions in either group. Although Marasco and colleagues $^{2}$ used ultrasonography to evaluate sternal instability, a more robust imaging modality such as computed tomography could have been more sensitive in detecting malunion. Furthermore, neither study included high-risk patients.

It is also important to point out that wire cerclage cannot be defined loosely in such comparisons. To compare wire cerclage with other modalities, we first need to standardize wire cerclage according to the available evidence. Through the years, various configurations of wire closure-simple, parasternal, transsternal, alternating, figure-of-eight, and others-have been studied, with varying results, and each technique has its firm adherents. There is thus no clear consensus regarding the best wire closure technique. ${ }^{4}$

Bioengineering studies in various synthetic and cadaveric models have shown that rigid sternal fixation with plates, based on orthopedic principles, provides better results than wire cerclage. A recent $\mathrm{RCT}^{5}$ and a recent meta-analysis ${ }^{6}$ have validated these findings in the clinical setting. These findings raise the question of whether there is any value in comparing sternal plates with ZIPFIX ties in the face of better results with rigid plate fixation.

In summary, both studies cited by Tam and Fremes ${ }^{1}$ suffer from reporting, attrition, detection, and selection biases. I completely agree with them that a better-planned

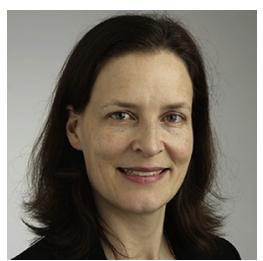

TO ZIP OR WIRE: AN ONGOING DEBATE

\section{Reply to the Editor:}

We thank Drs Tam and Fremes for their interest in our ZipFix sternal closure randomized controlled trial ${ }^{1}$ and for alerting us to a very similar trial published at the same time in Heart, Lung and Circulation. $^{2}$ As they point out, on first glance, the results appear somewhat divergent between the 2 trials, despite similar study designs. However, closer inspection of the study protocols offers some explanation as to the varied results seen.

In the study by Nezafati and colleagues, ${ }^{2}$ a single surgeon performed all the sternotomies and sternal closures. This is a strength of that study because it obviously reduces any variability between operators. In contrast, we had 3 surgeons performing sternal closure, which inherently introduces some variability.

The assessment of pain between groups was analyzed differently between the 2 studies, but the results are not that dissimilar. Both studies used a Visual Analogue Scale of 0 to 10 to assess pain, and in both studies, pain decreased over time as would be expected. In our study, these assessments were made by research staff blinded to the treatment arms, and pain was measured at days 1 and 3 postoperatively, the day of discharge, and 4 weeks postoperatively. Analysis of variance was performed, and the multivariable 